Matija Dronjić

Etnografski muzej

Zagreb

matija@emz.hr
DOI $10.32458 /$ ei.26.4

UDK 39:639.22](519.5)

639.2.057-055.2 (519.5)

39:930.85](519.5)

Prethodno priopćenje

Primljeno: 21. lipnja 2021.

Prihvaćeno: 19. srpnja 2021.

\title{
Kultura haenyeo s otoka Jeju kao primjer očuvanja nematerijalne kulturne baštine u Republici Koreji na nacionalnoj i međunarodnoj razini
}

\begin{abstract}
Autor predstavlja preliminarne rezultate istraživanja provedenoga tijekom petomjesečnoga studijskog boravka u Korejskom nacionalnom etnografskom muzeju 2017. godine u sklopu međunarodnoga programa profesionalne razmjene Inicijativa za kulturno partnerstvo (CPI) Ministarstva kulture, sporta i turizma Republike Koreje te dopunskoga istraživanja provedenoga samostalno tijekom 2019. godini, čiji je cilj bio proučiti korejski sustav očuvanja nematerijalne kulturne baštine i njegove efekte na vrlo specifičnom fenomenu nematerijalne kulturne baštine - tzv. kulturi haenyeo s otoka Jeju, tj. kulturi roniteljica s otoka Jeju - uvrštenom na UNESCO-ovu Reprezentativnu listu nematerijalne kulturne baštine čovječanstva 2016. godine i korejsku Nacionalnu listu nematerijalne kulturne baštine godinu dana poslije.
\end{abstract}

Ključne riječi: nematerijalna kulturna baština, haenyeo, ribarstvo, Jeju, Republika Koreja

\section{UVOD}

Ovaj tekst predstavlja moj treći prilog na temu očuvanja nematerijalne kulturne baštine u Republici Koreji u Etnološkim istraživanjima. U prvom sam se dotaknuo povijesnoga razvoja južnokorejskoga Sustava očuvanja nematerijalne kulturne baštine koji se pokazao kao vrlo učinkovit, ali ne i bez izazova (Dronjić 2017.). Drugi tekst fokusirao se na problematiziranje funkcioniranja Sustava na regionalnoj razini, na primjeru studije lokalne inačice predstave Park Cheomji Nori koja se izvodi na širem području grada Seosana, upisane na regionalnu listu nematerijalne kulturne baštine 
pokrajine Chuncheongnam (Dronjić 2020.). Funkcioniranje Sustava problematizira se i u trećem radu, ali na nacionalnoj i međunarodnoj razini, na primjeru fenomena tzv. haenyeo kulture s otoka Jeju, ambicioznoga i kompleksnoga poduhvata očuvanja življene kulture roniteljica s otoka Jeju (zvane haenyeo, ${ }^{1}$ jamnyeo ili jamsu). Haenyeo žive u većini obalnih sela na otoku (kao i na susjednim otočićima) i bave se izlovom morskih plodova (poput hobotnica, ježinaca, morskih krastavaca, kamenica, puzlatki, morske trave i dr.) ronjenjem na dah.

U radu donosim preliminarne rezultate etnografskoga istraživanja manjega opsega provedenoga u nekoliko etapa tijekom 2017. godine, u kojem sam sudjelovao kao dio istraživačkoga tima ${ }^{2}$ Korejskoga nacionalnog etnografskog muzeja, kao i kraće, samostalno provedene dopunske kampanje tijekom rujna 2019. godine. ${ }^{3}$ Istraživanje se temeljilo na metodi promatranja sa sudjelovanjem te nestrukturiranim razgovorima s haenyeo, predstavnicima zajednice, odnosno osobama zaduženima za provedbu plana očuvanja haenyeo kulture s otoka Jeju u kontekstu nematerijalne kulturne baštine.

S obzirom na to da sam se tijekom zadnjih desetak godina među ostalim fokusirao i na istraživanje efekata procesa pobaštinjenja (eng. heritagization) na temama lepoglavskoga čipkarstva i tzv. majdana, odnosno tradicijskoga kovačkog obrta na području središnje Bosne i Hercegovine, odlučio sam iskoristiti mogućnost koju mi je pružala stipendija i proširiti istraživanje na Republiku Koreju, zemlju koja je još polovicom prošloga stoljeća započela sa spomenutim procesima. Tim Odjela za istraživanja Korejskoga nacionalnog etnografskog muzeja (kao središnje muzejske institucije etnografskoga predznaka u Republici Koreji) prihvatio je prijedlog teme moga istraživanja te sam uz njihovu organizacijsku pomoć otišao na Jeju, gdje sam stupio u kontakt s nizom lokalnih institucija i pojedinaca uključenih u projekte očuvanja kulture haenyeo, koji su me posljedično upoznali sa samim baštinicama - roniteljicama i članovima njihovih obitelji. Unatoč činjenici da sam vrlo brzo uspostavio dobre odnose s njima, moju istraživačku poziciju nužno je okarakterizirati kao autsajdersku, poglavito radi jezične i kulturološke barijere. Međutim, mislim da sam do određene mjere uspio "opipati puls" zajednice i time ostvariti cilj istraživanja, ocrtati obris problematike očuvanja nematerijalne kulturne baštine u Republici Koreji na primjeru kulture haenyeo s otoka Jeju, što je ujedno i cilj ovoga priloga.

1 Danas najrasprostranjeniji naziv za roniteljice, dolazi od kor. 해 (hae) u značenju 'more' i 녀 (nyeo) u značenju 'žena'.

2 Srdačne zahvale kolegama iz Korejskoga nacionalnog etnografskog muzeja, abecednim redoslijedom: Cheon Jingji, Cho Haein, Choi Eunsoo, Jang Jang-sik, Kim Hyeongju, Kim Jongmin, Koo Mun Hoe, Lee Hyuna, Lee Kwan-Ho, Lee Nan-Young, Lee Yunha, Oh Changhyun, Oh Joonsuk, Park Hyeroung, Park Seonju, Sin Jeong Soo, Woo Seung Ha, Yi Kiwon te posebno Kang Kwon-yongu i kolegama iz Haenyeo Museuma koji su mi bili od velike pomoći kod samoga terenskog dijela istraživanja. Također, ovom bih prilikom zahvalio svim haenyeo s kojima sam razgovarao, na vremenu, srdačnom prijemu i strpljenju prilikom svladavanja jezičnih i kulturoloških barijera.

3 Nažalost, provedbu ovoga istraživanja mi je uvelike otežala sezona tajfuna. Tajfun Lingling je poharao Jeju nekoliko dana prije moga dolaska radi čega su odgođene pojedine javne manifestacije koje su bile u fokusu ove istraživačke kampanje, a posljedice nevremena su poremetile i svakodnevne aktivnosti haenyeo, kao i rad određenih ugostiteljskih objekata pod njihovim vodstvom. Naposlijetku, radi približavanja tajfuna Tapah odlučio sam prekinuti terensko istraživanje nekoliko dana prije nego što sam planirao te sam se vratio u Seoul gdje sam se posvetio arhivskim istraživanjima građe iz dokumentacije Nacionalnoga etnografskog muzeja Koreje. 


\section{KULTURA HAENYEO S OTOKA JEJU}

Jeju (kor. Jejudo) je najveći otok u Republici Koreji, smješten oko stotinjak kilometara od njezine južne obale. Prostire se na površini od $1.826 \mathrm{~km}^{2}$ i broji oko 670.000 žitelja, prepoznatljiv je po impozantnom Hallasanu, vulkanu u mirovanju koji s 1.947 metara nadmorske visine dominira vizurom otoka. Za njegove obale karakteristične su sive vulkanske stijene, oblikovane zahvaljujući izmjenama plime i oseke, morskim strujama te snažnim vjetrovima. Iako je u toplijim mjesecima Jeju omiljena turistička destinacija, zimi bi se obalni pojas otoka teško moglo opisati kao gostoljubivo mjesto, o čemu prvenstveno svjedoči tradicijska arhitektura - niske prizemnice skromnih dimenzija skrivene od vjetra unutar malih dvorišta opasanih visokim zidovima od tamnoga vulkanskog kamena. U takvu okružju razvio se fenomen haenyeo.

Historiografski izvori potvrđuju kako se na otoku Jeju ronilo u potrazi za hranom najkasnije od sredine prvog tisućljeća nove ere, dok prvi dokumenti koji govore o ženama u ulozi roniteljica datiraju u 17. stoljeće. Još uvijek nije u potpunosti jasno kada je i zbog čega ronjenje postalo isključivo žensko zanimanje, ali je sigurno da se profesionaliziralo tijekom tzv. japanskoga kolonijalnog perioda, odnosno između 1910. i 1945. godine (Hilty 2015: 17-19).

Zbog migracijskih procesa uzrokovanih ekonomskim razlozima koji traju od kraja 19. do otprilike sedamdesetih godina 20. stoljeća, postoje (ili su postojale) zajednice haenyeo na kopnenoj obali, Japanu, Kini (i kopnu i Tajvanu), pa čak i Rusiji. Da bi ih se razlikovalo od žena koje su ostale na otoku Jejuu, kolokvijalno se nazivaju chalga ${ }^{4}$ haenyeo.

S obzirom na to da je ronjenje postalo isključivo ženska ekonomska aktivnost, mnoge su se obitelji počele oslanjati na njihove prihode, čime haenyeo postupno preuzimaju ulogu hraniteljica koja je prije bila rezervirana za muške ukućane. Posljedično, taj je pomak stvorio specifičnu društvenu strukturu u kojoj je žena postala glava kućanstva, dok su muškarci na temelju strogih konfucionističkih društvenih normi nastavili dominirati javnom sferom.

Pojam kultura haenyeo obuhvaća skup kulturnih praksi i predmeta vezanih uz njihovu profesiju, kao i prostor (prirodni i kulturni) u kojem žive i rade. Vještina ronjenja na dah, zvana muljil, razvijena je tijekom dugogodišnje prakse te uključuje postizanje kapaciteta pluća dostatnoga za držanje daha do dvije minute, ${ }^{5}$ kao i sposobnost tijela da izdrži tlak i hladnoću vode. Haenyeo provodi roneći šest do sedam sati dnevno tijekom ljetnih mjeseci, odnosno četiri do pet sati dnevno u zimskim mjesecima. U prosjeku roni oko devedeset dana godišnje (UNESCO 2016., s.n. 2014: 17-24).

Još jedna zapanjujuća karakteristika jest formiranje mentalne mape podmorja, kao i korištenje lokalnoga, tradicijskim putem prenošenoga znanja o izmjeni plime i oseke te snažnim morskim strujama oko Jeju. Većina žena ne pouzdaje se u službene vre-

4 Pojam 잘가 (chalga) koristi se kao neformalan pozdrav na odlasku, "zbogom".

5 Također, kad haenyeo izranjaju na površinu, koriste se tehnikom brzoga izdisanja i udisanja koja ujedno proizvodi glasan zvuk sličan zvižduku koji se naziva sumbisori (Hilty 2015: 34). 
menske prognoze, već se prilikom planiranja zarona konzultiraju s iskusnijim ženama haenyeo koje se nazivaju sanggun. Iako su jedne drugima konkurencija, jako je razvijena međusobna briga te haenyeo gotovo bez iznimke uvijek rone u skupinama. Uz dubok osjećaj uzajamnoga poštovanja, postoji velika solidarnost prema manje fizički spremnima, mahom starijim haenyeo, kojima se dodjeljuju sigurniji dijelovi mora / podmorja (UNESCO 2016.).

Važan dio kulture haenyeo su šamanistički rituali namijenjeni bogovima mora kao što je jamsugut, izvođen kako bi se osigurala sigurnost i obilan ulov. Uz to, žene se mole na obrednim mjestima pokraj mora u kojem se nalaze haesindang (svetišta). Osim religijskog aaspekta kulture haenyeo s otoka Jeju, njihov folklorni izričaj također je vrlo važan, poput haenyeo norae, pjesama koje su se pjevale tijekom veslanja od obale do mjesta na kojem počinje zaron (UNESCO 2016.; s.n. 2014: 41, 49).

Ronilačka odjeća ima posebno značajnu ulogu za kulturu haenyeo s otoka Jeju, pogotovo u baštinskom kontekstu iz razloga što se mijenjala tijekom vremena. Mulot, tradicijska odjeća, sastojala se od tri elementa izrađena od pamuka: hlača (mulsojungi), jakne (muljeoksan) i poveza za kosu (mulsugun). Sustav odijevanja je vrlo specifičan radi bočnih otvora koji su olakšavali odijevanje, čak i trudnicama. Međutim, 1970-ih su uvedena gumena (kasnije neoprenska) ronilačka odijela zahvaljujući kojima su haenyeo mogle provesti dulje vrijeme pod vodom (Sl. 1.), što je stvorilo povećanje produktivnosti, a posljedično i prihoda (Kang i Kwon 2014.). Otprilike u isto vrijeme naočale koje su se koristile od 19. stoljeća zamijenjene su ronilačkim maskama. Što se tiče opreme, žene koriste tevak (pomagalo za plutanje, kako za haenyeo tijekom plivanja, tako i za zadržavanje mangsarija, mreže s prikupljenim morskim plodovima, na površini), utega i niza ručnih alata za potrebe berbe kao što su:

“...bitchang ili plosnati alat sličan tupoj oštrici noža ili dlijetu, čija je funkcija odvajanje puzlatki od podloge; jonggae-homi ili mali srp za rezanje morske trave i algi; seongge-kal ili nož sa širokom oštricom za uklanjanje ježinaca; gol-gaengi, mala motika za izvlačenje stvorenja iz pukotina u grebenima, okretanje malih stijena u potrazi za školjkama ili za pomoć prilikom kretanja duž grebena; homaengi ili kkakkuri, dugačka udica; jaksal ili koplje. Posljednja dva, korištena su za lov glavonožaca i ribe (umjesto skupljanja školjaka ili morskih algi), danas nisu u redovnoj upotrebi; gol-gaengi alatka je koja ima najviše namjena." (Hilty 2015: 32)

Bulteok je mjesto na kojem se haenyeo odmaraju i griju, pripremaju se za zaron i presvlače nakon obavljenog posla. U izvornom kontekstu, radi se o manjim suhozidnim strukturama bez krova u čijoj se sredini pali vatra. Međutim, od sredine 1980-ih neki su od njih zamijenjeni modernim objektima s tuševima i grijanjem, dok trenutno na otoku postoji oko 70 tradicijskih objekata (s.n. 2014: 37). Pored praktične svrhe, oni djeluju kao simbolički prostor ugrađen u obalni krajolik koji predstavlja prisutnost haenyeo. Štoviše, moderne inačice bulteoka su vrlo šarene i lako uočljive, zahvaljujući freskama koje prikazuju scene iz podmorja u kojima dominiraju žene koje rone.

Da je značaj haenyeo kulture na razini zajednice mnogostruk, vidljivo je u njihovom utjecaju na razvoj otoka (usp. Hilty 2016: 66). Prihod koji su žene ostvarivale u posebno 
određenim dijelovima mora kolektivnim radom nerijetko su koristile za komunalne projekte poput izgradnje škola. Duh solidarnosti između haenyeo i njihovih zajednica stvorio je sliku snažne i neovisne žene u korejskom društvu, inače vrlo usmjerenom na muškarce, pa su u novije vrijeme radi toga postale simbol rodne ravnopravnosti (usp. UNESCO 2016.). Haenyeo kultura s otoka Jeju također je izvanredan primjer održivog razvoja, zahvaljujući čemu se, uz sve ranije navedeno, savršeno uklapala u UNESCO-ov koncept nematerijalne kulturne baštine

"Zahvaljujući ekološkim metodama prikupljanja, rad haenyeo s otoka Jeju promiče održivost. Ljudska želja za velikim ulovom uravnotežena je ograničenim kapacitetom svakog pojedinca da ostane pod vodom bez pomoći opreme za disanje. Zajednica u cjelini odlučuje o broju dana za ronjenje svake godine, regulira radno vrijeme i minimalnu veličinu ulova te zabranjuje upotrebu pojedinih tehnologija kako bi se izbjegao neodrživi izlov. (...) Između haenyeo s otoka Jeju i njihovog ulova postoji simbiotski odnos. Redovito plijeve interdisalnu zonu kako bi pomogli morskim vrstama kod rasta, radi čega i nazuvaju more svojim "podvodnim poljem". (UNESCO 2016.)

\section{OČUVANJE KULTURE HAENYEO S OTOKA JEJU}

Trenutno na otoku Jejuu postoji oko 4.500 žena kulture haenyeo, a organizirani su u 102 seoske ribarske zadruge (nazivaju se eochongye) kojima vlasti Autonomne pokrajine Jeju ustupaju ekskluzivna prava za iskorištavanje obližnjih "podvodnih" ili "morskih" polja (morska područja smještena u blizini naselja) sukladno specifičnim zakonskim propisima. Udruženja haenyeo (tzv. haenyeohoe), povezane sa seoskim ribarskim zadrugama, dobrovoljne su organizacije koje djeluju kao udruge građana te kao kolektivi za gospodarsku proizvodnju. U okviru haenyeohoe raspravlja se o datumima sezone ronjenja, regulira se radno vrijeme, minimalna veličina ulova, metode i dinamika održavanja morskoga dna i dr. U većini slučajeva, odluke se donose konsenzusom članova.

Zlatnom erom smatraju se šezdesete godine 20. stoljeća, nakon čega slijedi dug period koji karakterizira konstantno smanjenje broja aktivnih haenyeo. Primjerice, godine 1966. bilo je 24.268 roniteljica, a taj broj 1970. godine naglo pada na 14.143. Razlozi svakako leže u tzv. Saemaul udong, tadašnjem vladinom programu za obnovu i razvoj koji je utjecao na promjenu ekonomske politike Autonomne pokrajine Jeju, što je rezultiralo naglom promjenom fokusa s poljoprivrede i ribolova na turizam. Pad broja haenyeo postaje relativno stabilan od 1980-ih, na oko 1.000 žena po desetljeću. U 2016. godini bilo je 4.005 aktivnih roniteljica, dok ih je 5.495 obustavilo ekonomske aktivnosti te su se vodile kao umirovljene. ${ }^{6}$ Ako se broj aktivnih haenyeo podijeli u dobne kategorije, razvidno je kako ih je oko $57 \%$ starije od 70 godina. Međutim, u kontekstu očuvanja kulture haenyeo s otoka Jeju zabrinjava činjenica da je prema nekoliko godina starim

6 Podatke je potrebno oprezno razmotriti jer kod haenyeo ne postoji službena dobna granica za umirovljenje. Neke žene rone u svojim osamdesetim godinama, tj. dokle god im to fizička spremnost i zdravlje dopuštaju (UNESCO 2016.). 
podacima samo 12 roniteljica u svojim 30-ima te 46 u 40-ima (Hilty 2015: 19; JSSGP 2017a; UNESCO 2016.).

Među haenyeo postoji stroga hijerarhija koja strukturira prema dugogodišnjem iskustvu i razini vještina. Najvještije žene nazivaju se sanggun i one su često voditeljice udruženja. Srednje kvalificirane nazivaju se junggun, a niže hagun. Budući da eochongye (seoska ribarska zadruga) ima isključiva prava za iskorištavanje mora i podmorja u blizini svojih sela, svatko tko želi roniti mora im se pridružiti i obratiti se relevantnoj udruzi haenyeo. Drugim riječima, eochongye i haenyeohoe prvenstveno su odgovorni za prijenos kulture haenyeo s otoka Jeju na mlađe generacije. Ronilačke vještine obično se prenose među ženama unutar obitelji, od majki do kćeri i od punica do snaha. Haenyeo može steći uvid u ronilačke vještine promatrajući iskusnije žene i s vremenom poboljšati vlastite vještine aktivnom vježbom. Međutim, budući da je ronjenje glavni izvor obiteljskih prihoda, nerijetko je slučaj da haenyeo odbije otkriti određene elemente svog znanja koje su neophodne za postizanje više razine stručnosti (UNESCO 2016.).

Nakon 1970-ih, izbor osobe da postane haenyeo u profesionalnom smislu postaje svjesna odluka, a ne tijek događaja koji se temelji na lokalnim/obiteljskim tradicijama. Ipak, zajednica haenyeo u svakom selu i dalje je igrala (i još uvijek igra) ulogu strukovne škole za novu kandidatkinju. Tome se 2008. godine pridružila Hansupul haenyeo škola u Hallimu (Jeju City), u kojoj se ronilačke vještine podučavaju na sustavniji način (UNESCO 2016.).

Uz zajednice haenyeo, i pokrajinska vlada na otoku Jeju provela je niz mjera očuvanja. Godine 2002. žene su uključene u sustav zdravstvenog osiguranja bez participacije (JSSGP 2015.), a 2017. godine na snagu je stupio Pravilnik kojim je omogućeno ženama starijim od 70 godina da dobiju 200.000 KRW (približno $150 €$ ) stalne mjesečne financijske potpore "za sprečavanje nesreća i očuvanje dohotka" i $500.000 \mathrm{KRW}$ (približno $370 €$ ) za osobe koje su trenutno u programu osposobljavanja ili su netom završile obuku te su mlađe od 40 godina (JSSGP 2017b). Donošenje spomenutog propisa može se pripisati osnivanju Provincijskog odbora za zaštitu kulture haenyeo s otoka Jeju 2011. godine, koji je ujedno osmislio prvi petogodišnji akcijski plan očuvanja (od 2011. - 2015.) (UNESCO 2016.).

Kultura haenyeo s otoka Jeju ili neki od njezinih elemenata uvršteni su na nekoliko listi nematerijalne kulturne baštine - korejskih (regionalnih i nacionalnih) i međunarodnih. Pjesma haenyeo (u smislu glazbenog folklornog izričaja) upisana je 1971. godine kao prva stavka na listi Nematerijalne kulturne baštine Provincije Jeju (Regionalna lista nematerijalne kulturne baštine Republike Koreje), godine 1980. ritual Yeongdeunggut uvršten je na korejsku Nacionalnu listu nematerijalne kulturne baštine pod rednim brojem 71, a 2009. godine uvršten je na UNESCO-ovu Reprezentativnu listu nematerijalne kulturne baštine čovječanstva. Također, odjeća i pribor koje žene koriste prilikom ronjenja zaštićeni su kao regionalna folklorna baština7 2008 . godine. Posebno zanimljiv moment je činjenica kako je međunarodno priznanje prethodilo

7 Više o konceptu folklorne; baštine kao kategorije u korejskom sustavu očuvanja nematerijalne kulturne baštine u Dronjić 2017: 12-13; Yim 2005: 1; Kim et al. 2012: 22. 
onome na nacionalnoj razini, tj. kultura haenyeo s otoka kao kulturni fenomen uvršten je na UNESCO-ovu Reprezentativnu listu 2016. godine, dok se na nacionalnoj listi isti našao godinu dana kasnije, pod rednim brojem 132 (JSSGP 2017a).

Kao značajan pozitivan pomak u praksi očuvanja smatra se otvaranje Haenyeo muzeja 2006. godine (JSSGP 2006.). Kompleks je smješten na istočnoj strani otoka, u mjestu Gujwa-eup, a sastoji se od dvije zgrade u kojima se nalaze tri stalna postava, dječji muzej, projekcijska i koncertna dvorana, te prostori za edukativne aktivnosti. Muzej se nalazi u naselju u kojem egzistira uspješna i vrlo aktivna haenyeo zajednica, a pored istraživanja, dokumentiranja, održavanja izložbi, obrazovnih programa i srodnih aktivnosti vezanih uz nematerijalnu kulturnu baštinu, od 2007. godine organizira godišnji Haenyeo festival s ciljem "ojačavanja samopoštovanja i potvrde vlastite vrijednosti kod roniteljica” (UNESCO 2016.).

Tijekom mog istraživanja imao sam priliku posjetiti Haenyeo muzej, u kojem sam razgovarao s tadašnjim kustosom Kang Kwon-yongom, članom zajednice i baštinikom haenyeo kulture s otoka Jeju. Osim što je strastveni istraživač, Kang je bio jedna od vodećih osoba u procesu očuvanja nematerijalne kulturne baštine povezane s elementima haenyeo fenomena te jedan od glavnih 'krivaca' odgovornih za njeno uvrštenje na UNESCO-ovu Reprezentativnu listu i Nacionalnu listu nematerijalne kulturne baštine Republike Koreje.

Glavna tema naših razgovora bili su izazovi s kojima se zajednica suočava, kao i budućnost haenyeo kulture s otoka Jeju. Razvidno je kako je glavni izazov u očuvanju ovog fenomena nematerijalne kulturne baštine stalno smanjenje broja haenyeo koje je usko povezano s pitanjem može li ronjenje biti održiva profesija. Trenutne projekcije prikazuju nastavak negativnog trenda, tj. kako će 2030. biti oko 2.000 aktivnih roniteljica. Interes za ovom profesijom prilično je nizak; trenutno se godišnje javlja između 30 i 40 novih haenyeo. Što se tiče (samo)održivosti kulture haenyeo s otoka Jeju u kontekstu ekonomske aktivnosti s baštinskim predznakom, jedan od glavnih izazova je relativno nizak prosječan dohodak (oko 1.000.000 KRW ${ }^{8}$ mjesečno), a većina žena ili nisu dovoljno obrazovane (uglavnom osnovnoškolska razina) ili su prestare da bi se upustile u poslovne projekte kojima bi proširile marginu dohotka. Međutim, neke haenyeo vode male obiteljske restorane, poput Park Sok-hui iz sela Gujwa, koju sam imao priliku upoznati te joj postaviti nekoliko pitanja. Naglašava povezanost između niskih primanja i niskog interesa za bavljenje ovom profesijom, navodeći kako je onima koje vode restorane - poput nje i njezine 34-godišnje kćeri, jedne od najmlađih haenyeo na otoku - prijeko potrebna dugoročno održiva financijska stabilizacija. Također, istaknula je da iako je zajednica ponosna na međunarodno priznanje ostvareno uvrštenjem na UNESCO-ovu listu, bolje obrazovane mlade žene vide svoju budućnost u sektoru turizma i povezanih usluga, daleko od teškog i opasnog života svojstvenog za roniteljice. 
Ae Duck Im, sociolog sa Nacionalnog sveučilišta u Jejuu, proveo je istraživanje s ciljem identifikacije mogućnosti za postizanje dugoročne održivosti profesije reevaluirajući rad roniteljica te je zaključio kako je potreban niz koraka kako bi se ronjenje uspostavilo kao održiva profesija u suvremenom kontekstu:

“...prvenstveno, potrebno je teorijska i praktična znanja o haenyeo profesiji sažeti u "haenyeologiju" kako bi služio za obrazovanje i obuku novih kandidatkinja. Drugo, svaka bi zajednica trebala osnovati školu za obuku haenyeo koja bi obučavala lokalne žene. Treće, takva bi škola trebala angažirati zajednicu i osnažiti haenyeo po pitanju njihovih prava, razvoja profesionalnosti, upravljačkih vještina, socijalne sigurnosti i vještina korporativnog upravljanja. Četvrto, haenyeo zajednice bi trebalo transformirati prema modelu društveno odgovornog korporativnog upravljanja. Peto, haenyeo zajednica bi trebala osnažiti samu sebe kako bi uspostavila sustav socijalne sigurnosti." (Im 2014: 59)

Lokalne vlasti poduzele su konkretne korake u tom smjeru donijevši Pravilnik o promociji haenyeo kulture 2014. godine. Kako bi se podigla razina vrijednosti haenyeo kulture, kako bi se doprinijelo lokalnom gospodarstvu čime bi se povećala kvaliteta života lokalnog stanovništva, namjera propisa bila je osigurati potrebne uvjete za njenu promociju i podršku ujedno u baštinskom/kulturnom kontekstu, kao i kontekstu ekonomske djelatnosti. Na taj je način lokalna vlada prepoznala haenyeo kulturu kao legitimnog dionika u ekonomskim granama vezanim uz iskorištavanje morskih resursa te je uspostavila niz mjera poput financijskih subvencija za razvoj i promociju njihovih proizvoda na širem nacionalnom, kao i inozemnim tržištima (JSSGP 2014.).

Tijekom istraživanja, daljnji razvoj turizma se nametnuo kao velika mogućnost, ali i najzahtjevniji izazov budućnosti. Budući da haenyeo more promatra na isti način kao poljoprivrednik vlastito polje, uslijedili su sukobi s turistima. Na primjer, moji sugovornici istaknuli su kako su zabilježene brojne svađe s pojedincima koji su išli u podvodni ribolov u vodama kojim upravlja određeni eochongye. Kang Kwon-yong naglasio je da se stvaranje veze između posjetitelja i lokalne zajednice ovisi o pomirenju tradicionalnih i suvremenih svjetonazora. Prema njegovom mišljenju, međusobno razumijevanje i poštovanje nešto je što treba početi graditi od lokalne razine, unutar zajednica. Kao moguće rješenje predlaže pilot-projekt uspostave ekomuzeja koji bi djelovao kao platforma za komunikaciju u oba smjera.

Također, izazov je i trajno smanjenje broja roniteljica. Prema Kangovom mišljenju, povećanje broja haenyeo u bilo kojem dugoročnom pogledu ovisit će o promociji haenyeo kulture s otoka Jeju u baštinskom kontekstu unutar samih zajednica. Svojevrsno "ikoniziranje" roniteljica bio je samo jedan korak akcijskog plana, koji se za sada pokazuje plodnim. Uvrštenje na UNESCO-ovu Reprezentativnu listu učinio je značajan pozitivan napredak u izgradnji identiteta i osjećaja samopoštovanja, kako za roniteljice tako i za njihove zajednice u cjelini. Učinci prestiža međunarodnog priznanja utječu 
čak i na chulga haenyeo, ${ }^{9}$ što je vidljivo iz sve veće vidljivosti haenyeo zajednica trajno nastanjenih u obalnom području kopnene Republike Koreje.

Haenyeo su postale simbol otoka Jeju. Uz ranije spomenute oslikane objekte kojima se koriste same roniteljice, $\mathrm{u}$ javnom prostoru lik haenyeo prezentira se na muralima u središtima gradova i sela, kao i putem brojnih stiliziranih skulptura ne nužno isključivo memorijalnog karaktera. Drugim riječima, mnoge skulpture ne prikazuju određenu haenyeo već su posvećene svim haenyeo u zajednici te služe kao svojevrsni vizualni podsjetnik na njihovo prisustvo i značaj za stanovnike otoka Jeju (Sl. 2.). Uz prepoznatljive vizualne motive otoka - dol hareubang skulpture, ${ }^{10}$ autohtonu pasminu konja (Jejuma) i crne svinje (Jeju heukdwaeji) te mandarine - haenyeo počinju vizualno dominirati i na suvenirskom asortimanu, npr. na razglednicama (S1. 3.), magnetima, platnenim torbama i sl. Radi se uglavnom o stiliziranim ilustracijama koje prikazuju žene u suvremenom kontekstu, u neoprenskim odijelima, čija je glavna vizualna karakteristika nemogućnost definiranja njihove dobi. Također, zanimljivo je napomenuti kako se na spomenute suvenire tijekom mog istraživanja 2017. godine moglo naići tek sporadično, dok sam ih već samo dvije godine kasnije, u ranu jesen 2019. godine zamjećivao na svakom koraku - od dolaska u zračnu luku, do suvenirnica na periferiji Jeju City-a. Drugim riječima, efekti obaštinjenja haenyeo kulture s otoka Jeju vrlo su brzo nakon upisa na UNESCO-ovu Reprezentativnu i korejsku Nacionalnu listu nematerijalne kulture postali evidentni u javnoj sferi kao posljedica promjene kulturnih politika i s njima povezanih akcijskih planova.

Nakon što je prvi petogodišnji plan postigao svoje ciljeve, u njegovom nastavku promišljalo se o unapređenju okvira očuvanja. ${ }^{11}$ Njegovi ciljevi koncipirani su kako bi osigurali uspješno srednjoročno i dugoročno očuvanje haenyeo kulture s otoka Jeju kao žive kulture (eng. living culture) i promovirali njezinu baštinsku vrijednost na nacionalnom i međunarodnom planu. Promocija ovog kulturnog fenomena zamišljena je da se temelji na njenoj reafirmaciji u suvremenom svijetu od strane lokalnih zajednica, a što se želi postići podizanjem promotivnih/obrazovnih aktivnosti za širu javnost, ali i za same otočane. Uz to, plan evocira potrebu za uspostavljanjem organizacije koja bi povezala sve zajednice i udruženja kako bi se poboljšao status nematerijalne kulturne baštine na nacionalnoj razini, budući da je nepostojanje izravne potpore središnje vlade uglavnom uzrokovano nedostatkom jednog takvog tijela koje bi služilo kao administrativna i operativna potpora. Nadalje, određene mjere uključuju provođenje dodatnih istraživanja i izgradnju baze znanja, postavljanje temelja za razumijevanje i zaštitu

9 Tijekom mog posjeta Busanu 2017. godine imao sam priliku kratko intervjuirati članice jedne od haenyeo zadruge "in situ", u improviziranom restoranu na plaži pod njihovim vodstvom. Isticale su velik ponos što su prepoznate u svjetskim razmjerima, kao i snažan osjećaj pripadnosti haenyeo kulturi otoka Jeju, bez obzira što su se trajno nastanile u Busanu prije pola stoljeća.

10 Velike skulpture izrađene od vulkanske (bazaltne) stijene koje prikazuju bogove koji su prema lokalnim vjerovanjima pružali zaštitu i plodnost. Postavljale su se ispred ulaza u imanja kako bi odvratile demone, radi čega su neke od njih visoke i do tri metra te su njihova lica nerijetko oblikovana u groteskne grimase.

11 Plan je koncipiran za razdoblje od 2017. do 2021. godine te je predložena visina budžeta za svih pet godina bila impresivnih 108.302.000.000 KRW (oko 81.000.000 €) (JSSGP 2017a: 43-51). Usporedbe radi, proračun Ministarstva kulture, sporta i turizma Republike Koreje za 2019. godinu iznosio je 6.48 trilijuna KRW (oko 4.65 milijardi €), tj. oko 10\% ukupnog državnog proračuna (Anderson 2019.). 
baštinskih lokaliteta vezanih uz morske ekološke resurse (veza između nematerijalne kulturne baštine i ekologije kao temelja održivog razvoja), aktiviranje međunarodne razmjene, izgradnje brenda i razvoj poslovnih modela koji bi osigurali stabilan izvor prihoda kako bi se kvaliteta života haenyeo dugoročno poboljšala (drugim riječima, potrebno je stvoriti održivu vezu između haenyeo kulture i uvjetno rečeno haenyeo ribarske industrije) (JSSGP 2017a).

\section{UMJESTO ZAKLJUČKA}

Pojam kulture haenyeo s otoka Jeju obuhvaća skup kulturnih praksi vezan uz specifičan oblik maritimne tradicijske ekonomike: izlova mekušaca, školjkaša i drugih morskih organizama metodom ronjenja na dah u kojem sudjeluju isključivo žene, od kojih su neke i u poodmaklim godinama. Spomenute prakse uključuju znanja, vještine i tehnike potrebne za izvršavanja fizički zahtjevnih i nerijetko opasnih zarona, kao i tzv. gut (rituale) ${ }^{12}$ kojima se zaziva dobar ulov i sigurnost na moru te folklorne oblike, odnosno pjesme koje haenyeo pjevaju prilikom odlazaka na more. Materijalna dimenzija kulture haenyeo s otoka Jeju nerazdvojna je od svoga nematerijalnoga pandana, a očituje se kroz specifičnu ronilačku opremu i pribor za lov / sakupljanje plodova mora te povezane arhitektonske elemente utilitarne ili ritualne namjene. Proces transfera znanja i vještina odvija se u obiteljima, školama, seoskim ribarskim zadrugama, udruženjima haenyeo te Haenyeo muzeju. Kultura haenyeo s otoka Jeju predstavlja karakter otoka i duh lokalnoga stanovništva, doprinosi unapređenju položaja žene u zajednici te promovira ekološku održivost primarno zahvaljujući ekoloških metodama i aktivnim uključivanjem zajednice u upravljanje ribolovnim praksama (UNESCO 2016.).

Radi veličine zajednice (prostorno i populacijski), kao i činjenice da na otoku Jejuu gotovo da i nema osobe koja na ovaj ili onaj način nije u nekoj direktnoj vezi s haenyeo (bilo da se radi o članu obitelji, sumještanki, poznanici itd.), kultura haenyeo predstavlja vrlo specifičan kulturni fenomen. Pristupajući iz pozicije istraživača koji se dugi niz godina bavi temama iz domene nematerijalne kulturne baštine, napose onih pojavnosti koje su usko vezane uz ekonomiku tradicijskoga predznaka, već sam pripremajući se za istraživanje uvidio kako se u ovom slučaju radi o jednom minuciozno promišljenom pristupu očuvanja nematerijalne kulturne baštine koji idejno pristupa zajednici kao temeljnom dioniku u kulturnim politikama u duhu UNESCO-ove Konvencije o zaštiti nematerijalne kulturne baštine (2003.), fokusirajući se primarno na suvremenost kulturnoga fenomena. I doista, baštinski aspekt i aspekt življene kulture postavljeni su konceptualno u ravnotežu, što je razvidno iz određenih elemenata - poetično rečeno napravljen je most preko tzv. wonhyeonga. ${ }^{13}$ Primjerice, koncepcijski balans moguće

12 Kor. 굿 (gut ili kut) je ritual kojeg izvodi šaman uz pjesmu, glazbu i ples nudeći božanstvima žrtvu u vidu hrane. Više u: Lee 1981.; Chung et al. (ur.) 2013.

13 U kontekstu nematerijalne kulturne baštine, tj. korejskoga Sustava očuvanja wonhyeong (arhetip) predstavlja specifičan pojavni oblik određenoga fenomena koji se smatra povijesno autentičnim, izvornim i nepromjenjivim te je njegova elaboracija osnova za uvrštenje na nacionalne ili regionalne liste nematerijalne kulturne baštine. Više u: Dronjić 2017.; 2020.; Yang 2003., 2004.; Lee 2012. 
je iščitati u odnosu "prošlih" žena kulture haenyeo (baštinski aspekt), odjevenih u tradicijsku, pamučnu odjeću, koje su monumentalizirane ili bolje rečeno muzealizirane u sklopu određenih spomenika i muzejskih postava, i "suvremenih" haenyeo (aspekt življene kulture) u neoprenskim odijelima koje su sveprisutne $\mathrm{u}$ javnom prostoru i predstavljaju simbol otoka Jeju. Drugim riječima, pobaštinjenje kulture haenyeo s otoka Jeju ne postiže se na temelju "arhetipa" već životne svakodnevice i realnih, možda je bolje kazati egzistencijalnih potreba članica zajednice. Postojeće haenyeo su svakako posebno osjetljiva skupina iz niza razloga: zbog prosječno visoke životne dobi; zbog opasnosti kojima su izložene tijekom svakoga zarona, ali i profesionalnih bolesti koje su posljedica cjeloživotne izloženosti varijabilnom tlaku i hladnoći morske vode; zbog krhkosti ekosustava koji se nalazi pod sve izraženijim naprezanjem uslijed klimatskih promjena i negativnih posljedica razvoja suvremenoga turizma na otoku i dr.

Turizam se u kontekstu održivosti kulture haenyeo s otoka Jeju javlja u dijametralno suprotnim ulogama, kao velika prilika i veliki izazov. S jedne strane, sva nastojanja predstavnika lokalnih vlasti da osiguraju optimalne uvjete za njegovo očuvanje (kroz legislativu, socijalne, infrastrukturne i operativne programe) u većoj ili manjoj mjeri su isprepletena s turističkim politikama, što uvelike nailazi na odobravanje zajednice. Primjerice, većina žena kulture haenyeo s kojima sam razgovarao, bilo da svoje proizvode prodaju na tržnicama, improviziranim restoranima na plažama ili su pak vlasnice malih obiteljskih restorana, svjesne su značaja razvoja turizma za dugoročno postizanje stabilnih prihoda te pozdravljaju povećanje turističkih kapaciteta koji bi im osigurali veće tržište. S druge strane, interesi krupnoga kapitala u turističkom sektoru nepovoljno djeluju na dugoročnu održivost krhkoga ekosustava, dok dijeljenje tradicijom utvrđenoga prava na more, odnosno "morska polja" s turistima izaziva sukobe ne samo na relaciji haenyeo - posjetitelji već i unutar članova malih zajednica.

Tijekom moga posjeta otoku Jejuu 2019. godine našao sam se u zanimljivoj situaciji na jednoj od najfrekventnijih turističkih lokacija na području Jeju Cityja, na plaži nedaleko popularne atrakcije Youngduam (stijena u obliku zmajeve glave) gdje lokalne haenyeo vode improvizirani restoran (Sl. 4.). Kada sam pristupio jednoj od starijih žena s namjerom da je zamolim za mjesto za kojim od malobrojnih stolova (na koje se inače nerijetko čeka), njezin pogled je odmah zastao na kameri koja mi je visjela $s$ ramena te mi je zapovjednim tonom zabranila fotografiranje. Odmah sam se ispričao te sam naglasio kako se radi o nesporazumu, kako ih nisam došao snimati već ručati i pritom priupitati par pitanja. Prihvatila je moju ispriku objeručke, a nakon što me posjela i poslužila, ona se ispričala objasnivši mi kako mnogo posjetitelja koji dođu na Younduam dolazi na plažu samo kako bi fotografirali njih i restoran, što smatra neprihvatljivim (bezobraznim) ponašanjem te lošim za posao. Tijekom našega kratkog razgovora, moja sugovornica je odvratila još nekoliko osoba od pokušaja fotografiranja, u pojedinim situacijama ne birajući uvrede.

Pitanja stvaranja baštine u kontekstu haenyeo s otoka Jeju dotaknula se Lee Inhye, antropologinja Nacionalnoga etnografskog muzeja Koreje. Polazeći od dileme konceptualizacije baštine - je li baština zajedničko vlasništvo ili osnovno sredstvo ostvarivanja ekonomske dobiti - kritički se postavila prema efektima stvaranja baštine zaključivši 
kako proces pobaštinjenja u slučaju fenomena kulture haenyeo s otoka Jeju u određenoj mjeri ipak utječe na identitet zajednice stvarajući prostore prijepora (Lee 2019.). Nužno je napomenuti kako njezina kritička analiza korespondira s rezultatima brojnih studija ${ }^{14}$ o efektima UNESCO-ove Konvencije o zaštiti nematerijalne kulturne baštine provedenih diljem svijeta u protekla dva desetljeća.

Konačno, nužno je postaviti pitanje je li kultura haenyeo s otoka Jeju primjer stabilnoga očuvanja nematerijalne kulturne baštine Republike Koreje na nacionalnoj i međunarodnoj razini? Ako se na pitanje pokuša odgovoriti pretpostavivši kriterij subjektivnoga dojma njezinih članova relevantnim (usp. Dronjić 2020: 31), ističe se nekoliko ključnih pogleda. S jedne strane, prestiž nacionalnoga i međunarodnoga priznanja odigrao je veliku ulogu u mobilizaciji zajednice i formiranju osjećaja ponosa, pripadnosti i kontinuiteta. Također, većina haenyeo pozdravljaju adresiranje otvorenih socijalnih pitanja (poput zdravstvenoga osiguranja i ostvarivanja prava na mirovinu), naglašavajući kako je put prema financijskoj stabilizaciji glavni preduvjet za dugoročnu opstojnost profesije. Zanimljivo, nekoliko žena istaknulo je i nezadovoljstvo ovim koracima, tvrdeći kako je financijska pomoć u određenoj mjeri kontraproduktivna jer utječe na njihov poduzetnički duh te ih transformira u turističke djelatnike i statiste u javnim manifestacijama poput Haenyeo festivala i sl. S druge strane, kao kriterij stabilnoga očuvanja nematerijalne baštine može se istaknuti i stabilizacija pada broja aktivnih haenyeo, odnosno postizanje održive razine. Iako se brojke popravljaju, one su daleko od idealnih, međutim mislim da je prilično iluzorno očekivati odraz efekta procesa očuvanja na ukupni broj žena kulture haenyeo u bilo kojoj perspektivi koja nije dugoročna.

U svakom slučaju, s obzirom na to da su ostala još mnoga otvorena pitanja koja bi trebalo istražiti, smatram iznimno nezahvalnim pokušavati dati konkretnije analize budućnosti očuvanja kulture haenyeo s otoka Jeju, pogotovo ako se uzmu u obzir još uvijek nesagledive posljedice globalne epidemije virusa SARS-CoV-2, koji će zasigurno ostaviti traga na kulturnim i turističkim politikama vezanim uz baštinu. Također, u ovom trenutku smatram da bi bilo nužno dodatno istražiti i učinke drugoga petogodišnjeg plana te detektirati nove izazove koji se formuliraju paralelno s njegovom provedbom. Konačno, sasvim je sigurno da kao nit vodilja i u ovoj situaciji može biti Halfsteinova ideja da očuvanje baštine nužno predstavlja očuvanje zajednice i njezine životne svakodnevice (Hafstein 2018: 164).

\section{LITERATURA I IZVORI:}

ADELL, Nicolas, BENDIX, Regina F., BORTOLOTTO, Chiara i Markus TAUSCHEK, ur. 2015. Between Imagined Communities and Communities of Practice. Göttingen: Universitätsverlag Göttingen.

14 Primjerice: Smith i Akagawa (ur.) 2009.; Akagawa i Smith (ur.) 2019.; Hafstein 2018.; Hameršak et al. (ur.) 2013.; Adell et al. (ur.) 2015. i dr. 
AKAGAWA, Natsuko i Laurajane SMITH ur. 2019. Safeguarding Intangible Heritage: Practices and Politics. London \& New York: Routledge.

ANDERSON, Andrew. 2019. "South Korea gets record-breaking budget". https://www. internationalartsmanager.com/news/arts/south-korea-gets-record-breaking-culturebudget.html (pristup 20.9.2021.).

CHUNG, Myung-sub, KIM, Tae-woo, AHN, Hye-kyeong, CHO, Hyun-sook i Seung-yu KIM. 2013. Encyclopedia of Korean Folklore and Tradicional Culture Vol. 2: Encyclopedia of Korean Folk Beliefs. Seoul: The National Folk Museum.

DRONJIĆ, Matija. 2017. "Kratak pregled sustava zaštite nematerijalne kulturne baštine u Republici Koreji”. Etnološka istraživanja 22: 9-25.

DRONJIĆ, Matija. 2020. "Seosanski Park Cheomji Nori kao primjer očuvanja nematerijalne kulturne baštine u Republici Koreji na regionalnoj razini”. Etnološka istraživanja 25: 23-33.

HAFSTEIN, Valdimar. 2018. Making intangible heritage: El Condor Pasa and Other Stories from UNESCO. Bloomington: Indiana University Press.

HAMERŠAK, Marijana. PLEŠE, Iva i Ana-Marija VUKUŠIĆ ur. 2013. Proizvodnja baštine. Kritičke studije o nematerijalnoj kulturi. Zagreb: Institut za etnologiju i folkloristiku.

HILTY, Anne. 2015. Jeju Haenyeo: Stewards of the Sea [Book I]. Jeju: Jeju Sea Grant Center.

HILTY, Anne. 2016. Jeju Haenyeo: Stewards of the Sea [Book II]. Jeju: Jeju Sea Grant Center.

IM, Ae Duck. 2014. "A Study on the possibility of Haenyeo as a Sustainable Profession with Social Security to keep tangible and intangible cultural heritage of Haenyeo community". World Environment and Island Studies 4 (3): 59-70.

JSSGP [Jeju Special Self-Governing Province]. 2006. 제주특별자치도해녀박물관 설치 및 운 영조례. Ordinance № 346, 5 March 2008; Wholly Amended by Ordinance № 1118, 31 December 2013.

JSSGP [Jeju Special Self-Governing Province]. 2014. 제주특별자치도 해녀문화산업 진흥 조례. Ordinance № 931, 18 July 2012; Wholly Amended by Ordinance № 1189, 21 April 2014.

JSSGP [Jeju Special Self-Governing Province]. 2015. 제주특별자치도 해녀 진료비 지원 조 례. Enacted by Ordinance № 150, 29 November 2006; Amended by Ordinance № 318, 9 January 2008; № 1518, 31 December 2015.

JSSGP [Jeju Special Self-Governing Province]. 2017a. 제2차 제주해녀문화: 보존 및 전승 5 개년 기본계획(안). Document.

JSSGP [Jeju Special Self-Governing Province]. 2017b. 제주특별자치도 해녀어업 보존 및 육 성에 관한 조례. Ordinance № 1870, 2 June 2017.

KANG, Kwon-young i Mi-seon KWON. 2014. The story of Jeju Haenyeo Clothing. Jeju: Haenyeo Museum.

KIM, Chang Gyoo; CHOE, Jong Ho; JEONG, Yu Gyeong i Gi-young JEONG ur. 2012. A Safeguarding System for Cultural Heritage in Korea: Focused on the Activities of Restoration, Transmission and Protection of Designated Cultural Properties. Daejon - Buyeo: CHA - NUCH. 
LEE, Inhye. 2019. "Issue of the Heritigization: Focusing on the Culture of Jeju Haenyeo Community". Intangible Heritage: a Challenge for Management and Collection Policy, 1720 October, Zagreb, Croatia.

LEE, Jung Young. 1981. Korean shamanistic rituals. Haag: Mouton Publishers.

LEE, Jung-yup. 2012. "Managing the trasnational, govrening the national. Cultural policy na the politics of the 'culture achetype project in South Korea"'. U: Popular Culture and the State in East and Southeast Asia, N. Otmagzin i E. Ben-Ari, ur., London \& New York: Routledge, str. 123-143.

s.n. 2014. Jeju Haenyeo. Jeju: Haenyeo Museum.

SMITH, Laurajane i Natsuko AKAGAWA ur. 2009. Intangible heritage. London \& New York: Routledge.

UNESCO [United Nations Educational, Scientific and Cultural Organization]. 2003. Convention for the safeguarding of the Intangible Cultural Heritage. Paris: UNESCO, 17. October.

UNESCO [United Nations Educational, Scientific and Cultural Organization]. 2016. "Nomination file № 01068 for inscription in 2016 on the Representative List of the Intangible Cultural Heritage of Humanity". https://ich.unesco.org/en/RL/culture-of-jeju-haenyeowomen-divers-01068 (pristup 20.6.2021.).

YANG, Jongsung. 2003. Cultural Protection Policy in Korea: Intangible Cultural Properties and Living National Treasures. Seoul - Edison: Jimoondang - Jimoondang International.

YANG, Jongsung. 2004. "Korean Cultural Property Protection Law with Regard to Korean Intangible Heritage”. Museum International 56 (1-2): 180-188.

YIM, Dawnhee. 2005. "Inventory Making Methodology for the List of Intangible Cultural Heritage in Need of Urgent Safeguarding: Korea's Experiences and Challenges". SubRegional Experts Meeting in Asia on Intangible Cultural Heritage: Safeguarding and Inventory-Making Methodologies, 13-16 December, Bangkok, Thailand. 